Accepted refereed manuscript of: March J, Rigby Dames B, Caldwell C, Doherty M \& Rafetseder E (2020) The role of context in "over-imitation": Evidence of movement-based goal inference in young children. Journal of Experimental Child Psychology, 190, Art. No.: 104713. DOI:https://doi.org/10.1016/j.jecp.2019.104713

(C) 2019, Elsevier. Licensed under the Creative Commons Attribution-NonCommercial-NoDerivatives 4.0 International http://creativecommons.org/licenses/by-nc-nd/4.0/

\title{
The role of context in "overimitation":
}

Evidence of movement-based goal inference in young children

Joshua March $^{\mathrm{a}^{*}}$, Brier Rigby Dames ${ }^{\mathrm{b} *}$, Christine Caldwell ${ }^{\mathrm{b}}$, Martin Doherty $^{\mathrm{c}} \&$ Eva Rafetseder ${ }^{\mathrm{b}}$

${ }^{a}$ School of Social Sciences, University of Dundee, United Kingdom, DD1 4HN

${ }^{\mathrm{b}}$ Faculty of Natural Sciences, University of Stirling, United Kingdom, FK9 4LA

${ }^{\mathrm{c}}$ School of Psychology, University of East Anglia, United Kingdom, NR4 7TJ

*These two authors (J. March and B. Rigby Dames) contributed equally to this paper

Joshua March is the corresponding author for this paper - all correspondence sent to j.j.march@dundee.ac.uk

Word count: 9064 words (inc. references: 10498 words) 


\section{Acknowledgements}

We extend our thanks to the children who participated in this study, their parents and the nursery staff involved. We also wish to thank Laura Maguire for her help with data collection. This research was made possible thanks to a PhD studentship attributed to the first author from the University of Stirling. Additionally, the third author was supported by the European Research Council (ERC) grant 648841 RATCHETCOG. 


\section{INTRODUCTION}

For many years researchers have studied why children reproduce actions that are not essential to achieving an external goal, a behaviour dubbed "over-imitation" (Gardiner, 2014; Lyons, Young \& Keil, 2007; McGuigan, Makinson \& Whiten, 2011). For example, if children watch someone tap a box before opening the box to retrieve a toy, children often copy the irrelevant tapping before opening the box (Horner \& Whiten, 2005). The crucial question is why children copy said irrelevant actions.

Key hypotheses put forward to explain over-imitation are (a) children mistakenly think the irrelevant action is causally necessary to achieve the goal (e.g., Lyons, Damrosch, Lin, Macris \& Keil, 2011; Lyons et al., 2007); (b) they regard the action as normatively prescribed (i.e., what they ought to do; e.g., Kenward, 2012; Keupp, Bancken, Schillmöller, Rakoczy \& Behne, 2016; Keupp, Behne \& Rakoczy, 2013); (c) they want to affiliate with the model by copying all their actions accurately, although they know the actions are not efficient (Nielsen, 2006; Nielsen \& Blank, 2011; Nielsen \& Tomaselli, 2010; Over \& Carpenter, 2012).

Whilst there is evidence supporting each theory (for a comprehensive review see Hoehl, Keupp, Schleihauf, McGuigan, Buttelmann \& Whiten, 2019) we argue for a fourth explanation, which we refer to as the movement-based goal inference account. Over-imitation occurs because children, like adults, can interpret inefficient, irrelevant movements as goals in themselves. When adults cannot see a clear external goal to a model's intentional action, they tend to infer movement-based goals, where they believe that the model's goal is simply to move in a certain way (Baker, Saxe \& Tenenbaum, 2009; Schachner \& Carey, 2013). Interpreting a model's movements as an independent, valid goal (e.g., dancing; ritualistic actions) could explain why adults - and children - imitate faithfully. 
Previous literature suggests that both adults and children attribute goals to other agents' actions. Adults naturally assume that movements are means to an end (e.g., Baker, Goodman \& Tenenbaum, 2008; Lombrozo, 2010; Schneider, Slaughter \& Dux, 2017) and that consequently the actions of others have goals (Froese \& Leavens, 2014). When adults see agents perform arbitrary actions without any relevant context (e.g., jumping up and down and from side-to-side), they are more likely to infer that the movements themselves were the goal (e.g., the agent wanted to dance) than when the same actions are performed in a relevant context (when the same agent manipulates objects by performing the exact same movements; Schachner \& Carey, 2013, Experiment 1; Novack, Wakefield \& Goldin-Meadow, 2016).

Schachner and Carey (2013) describe two factors encouraging movement-based goal inference in adults: when no external goals can explain the movement, or when actions are deliberate yet clearly inefficient towards achieving a known external goal. As over-imitation tasks often use "meaningless" actions (Horner \& Whiten, 2005; Hoehl et al., 2019), participants may attribute movement-based goals to these actions, leading to faithful imitation. The idea that the perceived 'inefficiency' of an action influences imitation is closely related to work on 'rational imitation' (Gergely, Bekkering \& Király, 2002; Gergely \& Csibra, 2003). Already 12-months-olds interpret actions as goal-directed and expect agents to realise goal-states in the most efficient way. They will imitate inefficient actions only when these actions cannot not be rationalised by any given constraints (Gergely et al., 2002, but see Paulus, 2012).

Movement-based goal inference can explain several findings from imitation research. Firstly, children copy actions more faithfully when these actions are presented as normative or conventional (Rakoczy, Warneken \& Tomasello, 2008; Keupp et al., 2013, 2016; Nielsen, Kapitány \& Elkins, 2015). Actions in over-imitation paradigms often involve some degree of repetition and inefficiency, which is indicative of movement-based goals. Secondly, identical 
actions are imitated differently depending on the goal that is attributed to them. Elsner and Pfeifer (2012) show that pre-schoolers' imitation of identical movements is determined by the presence of salient external goals. Actions performed without goals are more likely to be seen as performed for their own sake. Finally, young children imitate actions more faithfully if they believe those actions are causally irrelevant (Marsh, Ropar \& Hamilton, 2014). Although these findings provide only indirect evidence, they are predicted by the movement-based goal inference account of over-imitation.

Wakefield, Novack and Goldin-Meadow (2018) recently investigated whether young children infer movement-based goals as adults do. Models demonstrated actions either with objects (i.e., moving a ball into a box) or with no objects present (i.e., moving hands up and down). When 4- to 9-year-olds were asked what the models were doing, they were more likely to infer movement-based goals for the actions performed without external goals (when no objects were present). However, Wakefield et al. (2018) did not look at imitation. Investigating the link between movement-based goal inference and faithful imitation is therefore warranted.

Our paper aims to provide the first evidence that the factors leading to movementbased goal inference encourage faithful imitation in children. In three experiments, children were asked to imitate either body actions or actions on objects demonstrated by a model (similar to tasks by Carpenter, Call \& Tomasello, 2005, and Gleissner, Meltzoff \& Bekkering, 2000). The actions were performed either with or without external goals.

In our experiments the model always performed their actions in a specific manner: for example, when moving a coin into a box, the model hopped the coin across the table. It is this movement-style, this unusual manner of performing the action, which we use as the index of movement-based goal inference. If children copy the movement-style when replicating the 
action, then this indicates that they believed the movement-style was one of the model's goals. We predict that children are more likely to copy this movement-style if they believe the model was performing it for its own sake. In contrast, if children do not infer movementbased goals, then they should be less likely to imitate the movement-style.

Experiment 1 shows that children imitated movement-styles of actions lacking clear external goals (performed with 'no context') more faithfully than of actions with clear

external goals (performed with 'context'), replicating previous findings. Experiment 2 shows that the difference between these conditions was not due to the absence/presence of external goals, but also occurred when actions brought about external goals in a clearly inefficient way. Thus, the two conditions argued to increase movement-based goal inference also increased imitation fidelity. Experiment 3 controlled for the possibility that imitation fidelity was affected by the number of actions and objects present during the demonstration, as visual information has been argued to affect imitation (Leighton, Bird \& Heyes, 2010).

\section{EXPERIMENT 1}

Two- to five-year-olds saw object- and body-related actions performed in tasks modelled after Carpenter et al. (2005) and Gleissner et al. (2000). The actions were demonstrated either in the context of an external goal or without context. For instance, in one object-related task coloured coins were hopped either towards a box and slotted in (Context, $C)$ or towards a predefined location on the table (No Context, $N C$ ). In each condition the action demonstrated by the model was performed with a distinctive movement-style (e.g., hopping the coins across the table). Similarly, in the body-related tasks the experimenter performed a movement in a distinctive manner (e.g., crossing her arms and lifting them to shoulder height) that either had a visible goal (e.g., rubbing her shoulders) or did not (e.g., performed the arm action without touching her shoulders whilst holding her arms crossed). The movement-styles of each action 
were the crucial dependent variable. They were all unusual, inefficient ways of performing the actions. Movement-based goals should be inferred more in NC because the hopping movement does not lead to an external goal. We therefore predict that children will replicate movement-styles (e.g., the hopping movement) more often in $\mathrm{NC}$ than in $\mathrm{C}$ if they interpreted movement-styles to be a goal in themselves.

As well as recording movement-style imitation, we also recorded whether children imitated the end-state produced by the model. This would reveal whether focussing on the precise movements affected children's reproduction of the end-state. We predict that due to the nature of movement-based goal inference, imitation of end-states should be unaffected.

Three more details need to be added. Firstly, previous imitation research often used novel labels to help children focus on the tasks (Rakoczy et al., 2008; Keupp et al., 2013). To encourage greater attention, our tasks were introduced with novel labels (e.g., "wubsing"). Secondly, children between the ages of 2 to 5 years become increasingly likely to imitate faithfully (McGuigan et al., 2011; Moraru, Gomez \& McGuigan, 2016; Yu \& Kushnir, 2014). We therefore chose this age range and predict that, across both the $\mathrm{NC}$ and $\mathrm{C}$ conditions, older children would imitate movement-styles and end-states more faithfully than younger children. Finally, Kim, Óturai, Király and Knopf (2015) found that 18-month-olds imitate object-related actions more frequently than gestures, and are more likely to imitate objectrelated actions (but not gestures) leading to salient effects. We therefore predict that children should imitate the end-states more on object-related tasks than on body-related tasks. We also predict an interaction between context (C vs. NC) and task-type (body- vs. object-related). Children should show greater end-state imitation in $\mathrm{C}$ of the object-related tasks but in no other conditions, because it is only in this condition that visible objects could serve as reminders of what actions to perform (Elsner, 2007). 


\section{METHODS}

Participants. Participants were 30 children $\left(M_{\mathrm{age}}=47\right.$ months, $S D=12$ months $)$ in two age groups: 2 - to 3 -year-olds $\left(N=15,7\right.$ male, $M_{\text {age }}=38$ months, $S D=5$ months, range: $26-47$ months), and 4- to 5-year-olds $\left(N=15,6\right.$ male, $M_{\text {age }}=56$ months, $S D=8$ months, range: 48 -70 months). All parents gave written consent prior to their children participating in the study and debrief forms were provided. Ethical approval was granted by the Psychology Ethics Committee of the University of _.

Materials. Children were given four object-related tasks (Table 1A), each consisted of toys custom-made for the study. They were also shown four body-related tasks (Table 1B), consisting of everyday actions chosen based on previous studies (Gleissner et al., 2000; Stone, Ousley \& Littleford, 1997; Zmyj, Aschersleben, Prinz, \& Daum, 2012). Table 1 details the materials and actions involved in each task of Experiments 1 and 2. 


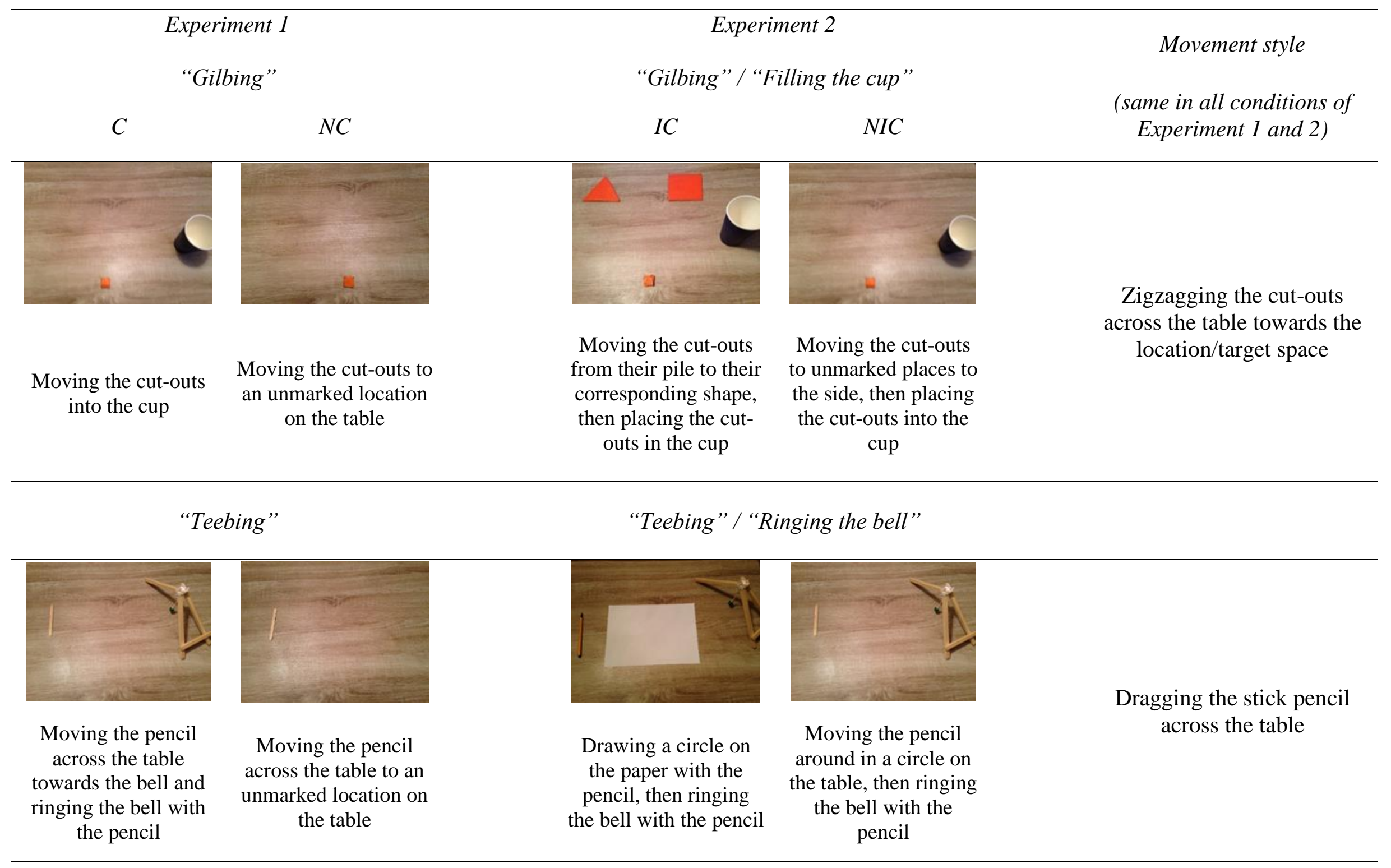




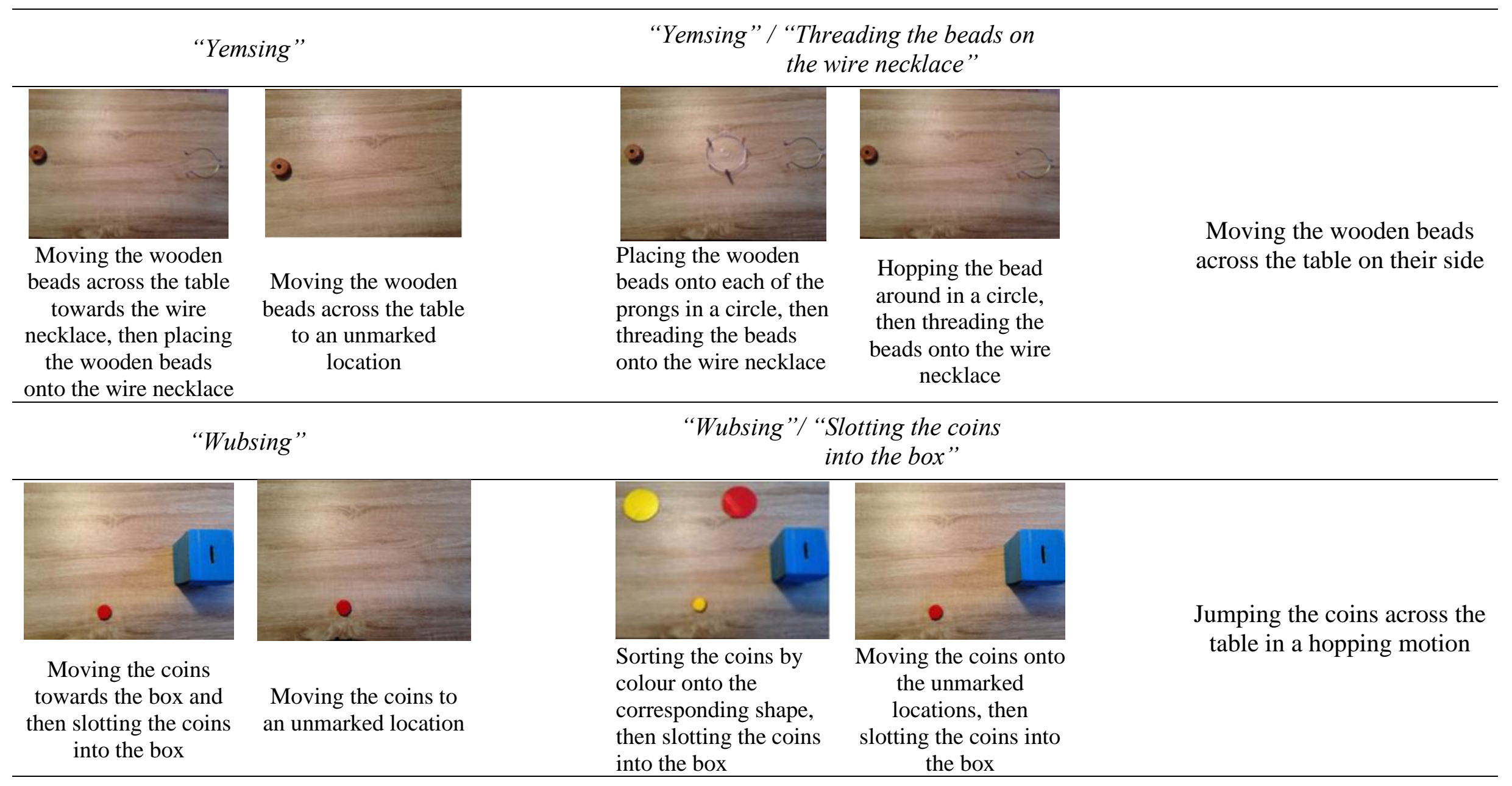

Table 1A. Descriptions of the actions and materials for the object-related tasks in Experiments 1 and 2 


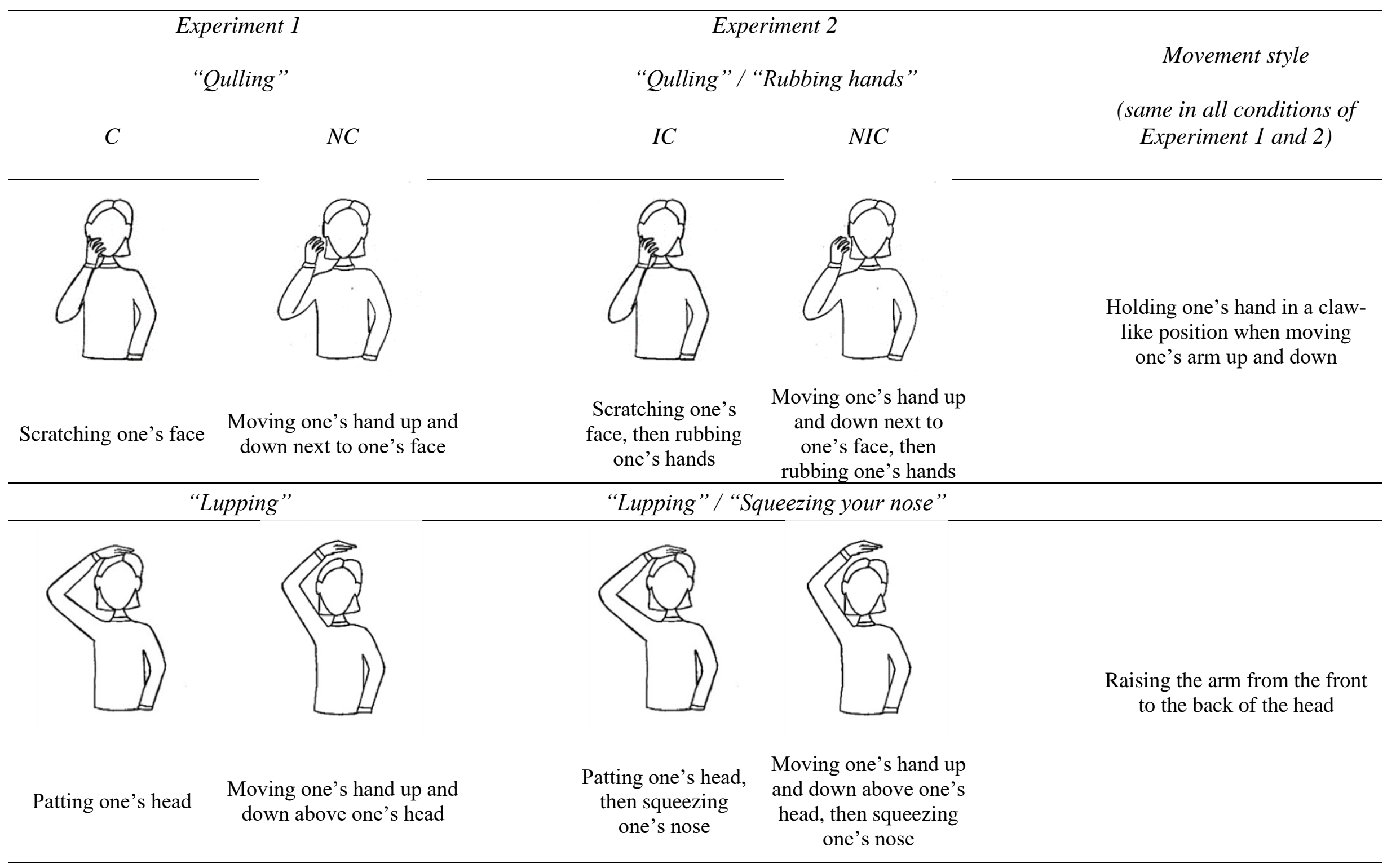




\begin{tabular}{|c|c|c|c|c|}
\hline \multicolumn{2}{|c|}{ “Zerping”" } & \multicolumn{2}{|c|}{ "Zerping" / "Clapping hands" } & \multirow[b]{2}{*}{$\begin{array}{l}\text { Holding one's arms } \\
\text { contralaterally when } \\
\text { rubbing/moving the arms } \\
\text { around one's shoulders }\end{array}$} \\
\hline & & & & \\
\hline \multirow[t]{2}{*}{$\begin{array}{l}\text { Rubbing one's } \\
\text { shoulders }\end{array}$} & $\begin{array}{c}\text { Crossing one's arms up } \\
\text { and down above one's } \\
\text { shoulders }\end{array}$ & $\begin{array}{l}\text { Rubbing one's } \\
\text { shoulders, then } \\
\text { clapping one's } \\
\text { hands }\end{array}$ & $\begin{array}{l}\text { Crossing one's arms } \\
\text { up and down above } \\
\text { one's shoulders, then } \\
\text { clapping one's hands }\end{array}$ & \\
\hline & "Daxing” & \multicolumn{2}{|c|}{ “Daxing” / “Rubbing tummy” } & \\
\hline Rubbing one's earlobes & $\begin{array}{l}\text { Rubbing one's fingers } \\
\text { together above one's ears }\end{array}$ & $\begin{array}{l}\text { Rubbing one's } \\
\text { earlobes, then } \\
\text { rubbing one's } \\
\text { tummy }\end{array}$ & $\begin{array}{l}\text { Rubbing one's fingers } \\
\text { together above one's } \\
\text { ears, then rubbing one's } \\
\text { tummy }\end{array}$ & \\
\hline
\end{tabular}

Table 1B. Descriptions of the actions for the body-related tasks in Experiment 1 and 2 
Design. Each child participated in eight tasks: four object-related tasks and four body-related tasks labelled by novel words (e.g., "wubsing”). The most important factor, varied withinsubjects, was the context in which the action was presented: In the context-present condition (C) actions (e.g., hopping coins) had a clear external goal (slotting into the box), while in the context-absent condition (NC) actions were performed without clear goals (e.g., the coins were hopped towards a pre-defined, unmarked location on the table). Critically, actions were identical in both conditions. Each child saw two NC object-related tasks, two NC bodyrelated tasks, two $\mathrm{C}$ object-related tasks and two $\mathrm{C}$ body-related tasks. The order of the bodyand object-related tasks was counterbalanced between children. The order of C and NC was counterbalanced using a Latin Square Design.

Procedure. Children were tested individually in a separate room at their nursery.

Object-related tasks. The experimenter said "Now I am going to show you something - this is how I wubs". The experimenter demonstrated the action with a specific movementstyle (e.g., hopping). In $\mathrm{C}$ the action had a clear context (e.g., slotting coins into a box), whereas in $\mathrm{NC}$ the same movement had no context. After the first demonstration the experimenter reset the apparatus and repeated the demonstration two more times, saying "Now I will show you again" and "One more time". The three demonstrations took under 30 seconds to perform.

Body-related tasks. Body-related tasks followed the same procedure as object-related tasks, but with no objects involved. For example, in $\mathrm{C}$ the experimenter rubbed her shoulders, whilst in NC, the experimenter just moved her arms up to shoulder height and moved her hands in a rubbing motion without contact. In both conditions, actions were performed with a specific movement-style: for example, the experimenter crossed her arms. 
Coding. Coding was performed in situ by the experimenter. In the object-related tasks, children received a score of 1 , if they pushed the shape left and right without breaking contact with the table (Gilbing), dragged a stick on its side without breaking contact with the table (Teebing), pushed the wooden bead across the table without breaking contact (Yemsing), and made the coins break contact with the mat more than once (Wubsing; see Carpenter et al., 2005). In the body-related tasks, they received a score of 1 if they curled the fingers to perform a scratching hand movement (Quilling), rubbed their head from front to back (Lupping), moved their arms ipsilaterally (Zerping), and rubbed their earlobes bimanually (Daxing).

If the child did not start by demonstrating the movement-style, but then corrected themselves, they received a score of 1 . However, mixtures of movements, for example jumping and zig-zagging the object, were coded 0.

As well as movement-styles, we recorded whether children imitated the end-state demonstrated by the model. For example, on the Wubsing task, if children placed the coin in the box/at the pre-defined location on the table, they were counted as imitating that end-state and received a score of 1 (regardless of whether they had imitated the movement-style). If they attempted but did not complete the end-state, they received a score of 0.5 . If they did not imitate or if they performed an unrelated action, they received a score of 0 .

\section{RESULTS}

Preliminary Analyses. There was no effect of task-order (object-related tasks first vs. bodyrelated tasks first) on movement-style or end-state imitation, all $p s>.24$. Girls and boys imitated at similar rates on all tasks for movement-style and end-state imitation, all $p \mathrm{~s}>.22$. For context-order ( $\mathrm{C}$ first vs. $\mathrm{NC}$ first) there was one significant interaction with context for movement-style imitation, $p=.045$. However follow-up analyses with Bonferroni corrections 
$(p=.025)$ revealed no significant effect, all $p \mathrm{~s}>.014$. There were no other significant effects of context-order, all $p s>.08$. These variables were not considered further.

Movement Style Imitation. Figure 1A shows imitation accuracy for movement-styles, split for context, task-type and age-group.
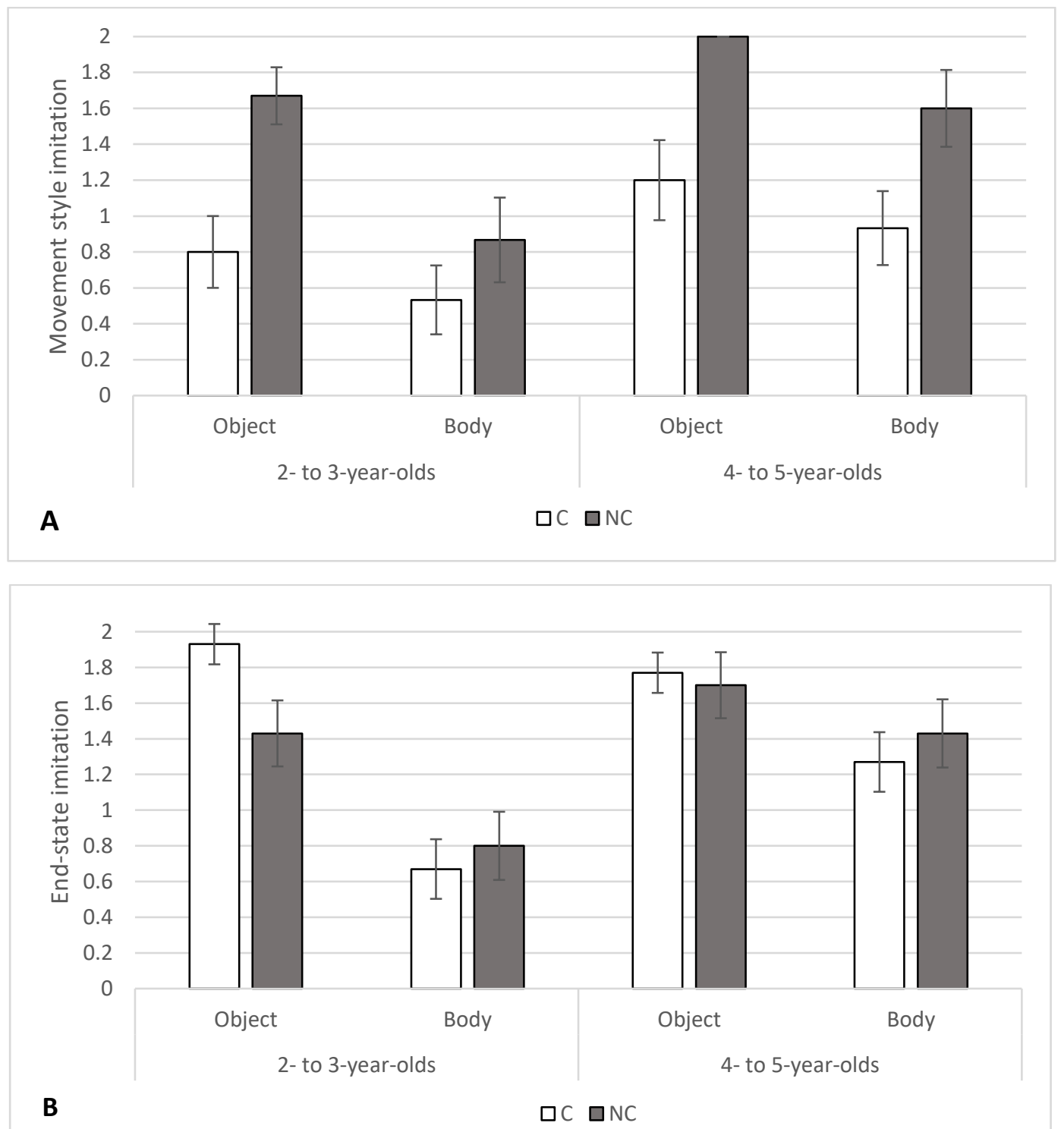

Figure 1. Imitation scores split for context (white bars: context-present; dark bars: contextabsent), task-type and age-group. 1A: Movement-style. 1B: End-state. Bars indicate standard errors. 
A 2 (context: context C vs. no context NC; within-subjects) $\times 2$ (task-type: objectrelated vs. body-related, within-subjects) $\times 2$ (age-group: 2 - to 3-year-olds vs. 4- to 5-yearolds, between-subjects) mixed factorial repeated-measures ANOVA was conducted on the imitation scores of movement-styles. We found a significant main effect of context, $F(1,28)$ $=24.03, p<.001, \eta^{2}=.46$, with more faithful imitation of movement-styles in NC $(M=1.53$, $S E=.10)$ than in $\mathrm{C}(M=0.87, S E=.13)$. We also found a significant main effect of tasktype, $F(1,28)=11.21, p=.002$, partial $\eta^{2}=.29$, and a main effect of age-group, $F(1,28)=$ $6.61, p=.016$, partial $\eta^{2}=.19$. Children imitated movement-styles more faithfully on objectrelated tasks $(M=1.42, S E=.10)$ than on body-related tasks, $(M=0.98, S E=.13)$ and the older children $(M=1.43, S E=.13)$ were more accurate than the younger children $(M=0.97$, $S E=.13)$.

There was a significant interaction between context and task-type, $F(1,28)=4.80, p=$ .037 , partial $\eta^{2}=.15$. Bonferroni corrected t-tests $(p=.025)$ showed that on object-related tasks children imitated movement-styles more faithfully in $\mathrm{NC}(M=1.83, S E=.08)$ than in $\mathrm{C}$ $(M=1, S E=.15), t(29)=5.77, p<.001$, Cohen's $d=1.05$. On the body-related tasks, children too imitated movement-styles more faithfully in $\mathrm{NC}(M=1.23, S E=.159)$ than in $\mathrm{C}$ $(M=.73, S E=.141), t(29)=3.04, p=.005$, Cohen's $d=.55$. But the mean difference was greater on the object-related tasks $\left(M_{\text {diff }}=.83\right)$ than on the body-related tasks $\left(M_{\text {diff }}=.5\right), p=$ .039. No other interactions were significant, $p>.19$.

End-state imitation. The same mixed factorial repeated-measures ANOVA was conducted on end-state imitation scores. We found no main effect of context, $F(1,28)=.578$, $p=.453$, partial $\eta^{2}=.02$, but a main effect of task-type, $F(1,28)=21.02, p<.001$, partial $\eta^{2}=$ .429 , and of age-group, $F(1,28)=5.32, p=.029$, partial $\eta^{2}=.16$. Children copied the endstates more in object-related tasks $(M=1.71, S E=.089)$ than in body-related tasks $(M=1.04$, 
$S E=.115)$ and the older children $(M=1.54, S E=.102)$ imitated end-states more faithfully than the younger children $(M=1.21, S E=.102)$.

Context interacted significantly with task-type, $F(1,28)=7.82, p=.009$, partial $\eta^{2}=$ .218. However, Bonferroni corrected t-tests $(p=.025)$ showed that the difference in end-state imitation scores was neither significant for object-related tasks (NC: $M=1.57, S E=.131 ; \mathrm{C}$ : $M=1.85, S E=.08, p=.035)$, nor for body-related tasks $(\mathrm{NC}: M=1.12, S E=.145 ; \mathrm{C}: M=$ $.97, S E=.129, p=.174)$. No other interactions were significant, all $p \mathrm{~s}>.06$.

Children occasionally failed to reproduce the end-state. To account for any influence of end-state imitation on movement-style imitation, we calculated a percentage score by dividing the number of trials on which children copied the movement-style by the number of trials on which they copied the end-state. The same ANOVA using this percentage score replicated the main effect of context on movement-style imitation, $F(1,28)=17.31, p<.001$, partial $\eta^{2}=.382$. Children copied the movement-style more in NC $(M=.733, S E=.058)$ than in $\mathrm{C}(M=.408, S E=.062)$. Using this conservative measure, no other main effects or interactions reached significance, all $p \mathrm{~s}>.06$.

\section{DISCUSSION}

Consistent with previous studies (Bekkering, Wohlschläger \& Gattis, 2000; Carpenter et al., 2005), children copied movement-styles (e.g., hopping), but not end-states, more accurately when external goals were absent. The goal-directed account of imitation (Bekkering et al., 2000) suggests that when children perceive an external goal, they prioritise reproducing said goal rather than copying precise movements. Only when external goals are absent do children copy movements faithfully. Yet our data show that when end-state imitation was controlled for by using only valid trials, children still imitated movement-styles more precisely in NC, 
where there was no external goal. This suggests that imitating movement-styles less precisely was not just a matter of viewing external goals as more important than means.

The difference between movement-style imitation in $\mathrm{NC}$ and $\mathrm{C}$ was particularly pronounced on object-related tasks. Kim et al. (2015) report that object-related actions are imitated more precisely than gestures, and we replicated this for both end-goal and movement-style imitation. Salient objects may facilitate action encoding and retrieval (Elsner, 2007). Already 2-year-olds are less likely to copy actions lacking salient goals (Yu \& Kushnir, 2014). Yet in our study movement-style accuracy was enhanced in context-absent conditions, when salient objects were removed. It is possible that children showed improved recall in the absence of distracting objects. The objects could have made children focus on reproducing the end-state instead of the movement-style. However, the difference between $\mathrm{NC}$ and $\mathrm{C}$ was not significant for end-state imitation on the object-related tasks. Furthermore there was a significant difference between $\mathrm{NC}$ and $\mathrm{C}$ on movement-style imitation for the body-related tasks, where children could not have been distracted by the presence of objects in $\mathrm{C}$ more than NC. This difference was also significant when using the percentage scores to control for end-state imitation. These findings speak against the possibility that memory resource limitations drove the context effects observed in Experiment 1, although we cannot rule this out for the object-related tasks (to control for this see our Experiment 2).

Finally, age affected both end-state and movement-style imitation. It is widely observed that imitation fidelity increases with age (McGuigan et al., 2011; Moraru et al., 2016; Yu \& Kushnir, 2014), which has been interpreted as older children imitating faithfully for social reasons. Given our results, where age did not interact with context or task-type, this interpretation seems plausible. The fact that end-state and movement-style imitation were equally affected by age additionally challenges the idea that memory limitations may prevent younger children from copying precisely. 
Taken together, Experiment 1 fully replicates several previous findings, providing a good foundation to investigate our next question: whether children would imitate an action's movement-style more faithfully if it achieved an external goal, but in an inefficient manner.

\section{EXPERIMENT 2}

Schachner and Carey (2013) proposed that movement-based goals are not only inferred for actions without external goals, but also when an external goal is achieved in a deliberately inefficient way. In their third experiment, adult participants were shown a video of a character holding a star. This character either jumped towards a star-marked box or jumped towards and away from the box. Adults were more likely to infer movement-based goals for the character jumping back and forth, which appeared inefficient towards a visible external goal.

Experiment 2 investigated whether children would imitate actions more faithfully when these actions achieved an external goal inefficiently, versus when they achieved an external goal efficiently but via an intermediate-state. This tests the second claim of the movement-based goal inference account: movement-based external goals can be inferred in the presence of visible external goals, but only when these are achieved inefficiently. The findings from Experiment 1 suggest that perceiving an action as lacking a visible external goal encouraged movement-style imitation. Here we investigate whether action inefficiency also encourages this effect.

Experiment 2 modified the tasks from Experiment 1 by having the experimenter either demonstrate an additional intermediate goal (IC condition) or not ( $N I C$ condition) before achieving a clear external end-goal (see Figure 2). In IC of the Wubsing task, for instance, the coins were now hopped towards colour-matched plates (intermediate goal), while in NIC the coins were hopped towards a blank, predefined location (no intermediate goal), before being 
slotted into a box in both conditions (end-goal). Importantly, the hopping action was now always directed diagonally away from the box such that the action appeared particularly inefficient in NIC, because it did not achieve an intermediate goal.

NIC of Experiment 2 closely resembles classic over-imitation tasks, which typically include actions lacking a clear external effect (e.g., coins are hopped to a nondescript location), but which eventually lead to an observable end-goal (e.g., slotting those coins into a box), making the intermediate action appear arbitrary and potentially inefficient towards the end-goal. In contrast IC of Experiment 2 can be interpreted as an external end-goal achieved via an unrelated intermediate goal. The comparison of these two conditions tests two predictions:

Firstly, as movement-based goals are inferred for actions that are inefficient in bringing about a goal, we predict that, if children inferred movement-based goals, they should imitate movement-styles (e.g., hopping) more faithfully in NIC than in IC.

Secondly, if the findings in Experiment 1 were driven by memory capabilities, children should now show lower imitation fidelity for end-goals in IC than in NIC. As the actions in NC of Experiment 1 lacked an external goal, there was less to remember and children may have simply found it easier to remember the movement-styles (Bekkering et al., 2000). Now that there were two external goals (intermediate and end) in IC, children may imitate the end-goal of the action sequence less in IC than in NIC where this was the only end-goal. We therefore recorded reproduction of the intermediate-state (sorting coins) and the end-goal (e.g., slotting into the box) alongside movement-style imitation.

Experiment 2 additionally looked at the effect of labels by varying the way the model referred to their actions. The model either called the task by a novel label (e.g., "wubsing") or by its end-goal (e.g., "slotting the coin into the box"). Previous research suggests that 
describing an action by its end-goal encourages children to imitate that goal (e.g., Gardiner, 2014; Elsner \& Pfeifer, 2012). We therefore predicted that children hearing the end-state label would be more likely to copy the end-goals of the tasks. We did not anticipate an effect of verbal frame on intermediate-state or movement-style imitation. 
Context $C$

No context $N C$

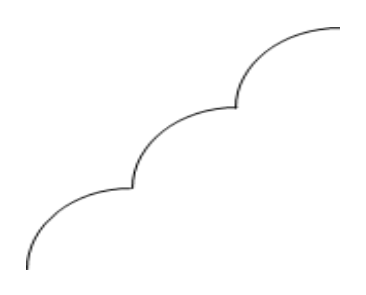

Action: Moving the coins towards the box

Movement-style: Hopping the coins
Action: Moving the coins across the table towards a predefined location Movement-style: Hopping the coins

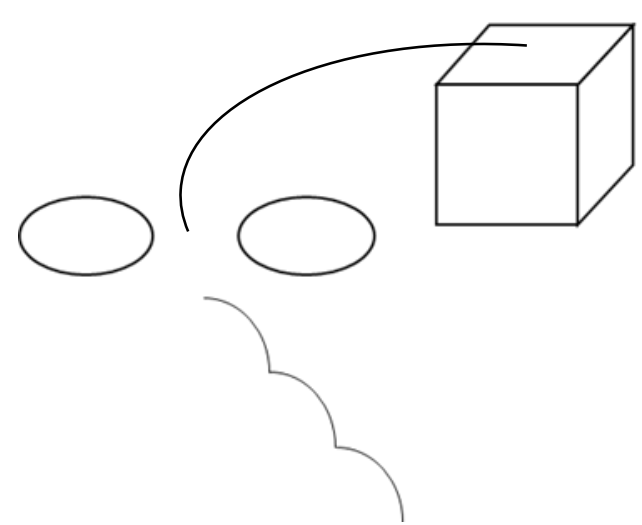

Action: Moving the coins to the plates, and then from the plate slotting the coins in the box

Movement-style: Hopping the coins
No intermediate context NIC

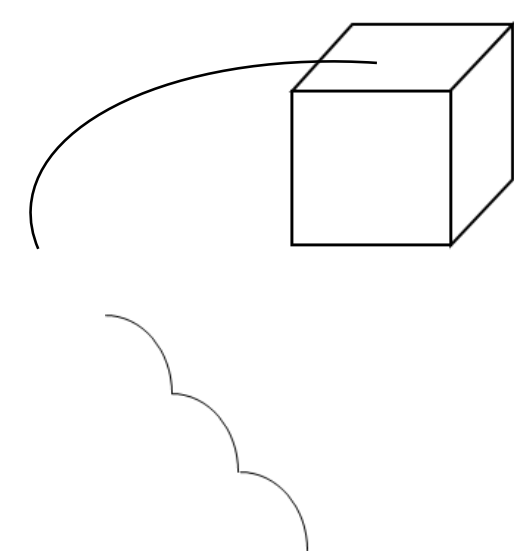

Action: Moving the coins across the table towards a predefined location, then slotting the coins in the box Movement-style: Hopping the coins

Figure 2. Set-up of the "Wubsing" task across Experiment 1 and Experiment 2. 


\section{METHODS}

Participants. Participants were 29 children aged 2 to 3 years $\left(15\right.$ males, $M_{a g e}=40$ months; $S D=5$ months, range: 31 - 48 months $)$ and 29 children aged 4 to 5 years (14 males, $M_{\text {age }}=$ 58 months $S D=7$ months, range: $48-71$ months). Children were randomly assigned to either the novel frame $\left(n=30,12\right.$ males, $M_{\text {age }}=48$ months $S D=10$ months, range: $31-67$ months) or the end-state frame $\left(n=28,16\right.$ males, $M_{\text {age }}=50$ months $S D=11$ months, range: $34-71$ months). The age of children in the novel and end-state frames were not significantly different, $p=.339$. Ethical approval was granted by the Psychology Ethics Committee of the University of _.

Materials. Experiment 2 used the same materials as Experiment 1. Additional custom-made materials were used for the new intermediate goal (e.g., coloured plates). Table 1 details the materials and actions involved in each of the tasks.

Design. Each child participated in four object-related tasks and four body-related tasks. Half of the children received the tasks using novel names (novel frame condition), for example "wubsing", and half received the tasks naming the effect of the last action in the sequence (end-state frame condition), for example "slotting coins into the box". Context was varied within-participants, so each child saw two NIC object-related tasks, two NIC body-related tasks, two IC object-related tasks and two IC body-related tasks. The order of context (IC vs. NIC) was varied between-subjects using a Latin Square Design.

Procedure. Each child was tested individually in a separate room of the nursery.

Object-related tasks. The experimenter began by saying: "Now I am going to show you something - this is how I wubs/slot the coins into the box". The experimenter performed an action with a specific movement-style (e.g., hopping), as in Experiment 1. In IC the first action had a clear context, such as sorting coloured coins onto corresponding coloured plates 
(intermediate-state), whereas in NIC the same sequence of movements was used without such a context (e.g., the plates were absent). In both conditions the coins were finally slotted into the box (end-goal).

Body-related tasks. The experimenter said: "Now I am going to show you something - this is how I lupp/clap my hands". The experimenter demonstrated the same actions as in Experiment 1, but finished with an additional external goal, for example, by clapping her hands.

Coding. Coding was performed in situ by the experimenter. Coding for movement style imitation was conducted in the same way as in Experiment 1. Children were additionally coded on whether they imitated the intermediate action (e.g., hopping the coin/rubbing one's earlobes) and the final action (e.g., slotting the coin into the box/rubbing one's tummy) in each task. For both the intermediate and final actions, if children completed the goal, they received a score of 1 . If they attempted but did not complete the goal they received a score of 0.5. Otherwise they received a score of 0 . Scores were coded separately for body-related tasks and object-related tasks.

\section{RESULTS}

Preliminary analyses. There were no significant effects of gender on any scores, all $p \mathrm{~s}>.2$. For context-order there was one significant interaction, $p=.045$, and there were significant interactions for task-order, $p=.031$ and $p=.035$. However follow-up analyses with Bonferroni corrections $(p=.025)$ revealed that none of these were significant, all $p s>.03$. There were no other significant effects of context-order or task-order, all $p s>.15$. These variables were not considered further. 
Movement-style imitation. Figure 3 displays imitation of movement-style (A), intermediatestate (B) and end-goal (C), split for context (NIC vs. IC), task-type (object-related vs. bodyrelated), and age (2- to 3-year-olds vs. 4- to 5-year-olds).

A 2 (context: intermediate context IC vs. no intermediate context NIC; withinsubjects $) \times 2$ (task-type: object-related vs. body-related, within-subjects $) \times 2$ (age -group: 2 to 3-year-olds vs. 4- to 5-year-olds, between-subjects) x 2 (verbal frame: novel label vs. endstate label, between-subjects) mixed factorial repeated-measures ANOVA was conducted on movement-style imitation. Replicating Experiment 1, there was a significant main effect of context, $F(1,54)=43.73, p<.001$, partial $\eta^{2}=.45$. Movement-styles were imitated more faithfully in NIC $(M=1.42, S E=.07)$ than in IC $(M=0.93, S E=.07)$. There were significant main effects of task-type, $F(1,54)=11.23, p=.001$, partial $\eta^{2}=.17$, and age-group, $F(1,54)=$ $10.17, p=.002$, partial $\eta^{2}=.16$. Movement-style imitation was greater for object-related tasks $(M=1.35, S E=.06)$ than for body-related tasks $(M=1.00, S E=.09)$, and the older children $(M=1.35, S E=.08)$ imitated more accurately than the younger children $(M=0.99, S E=$ $.08)$. There was no main effect of verbal frame, $F(1,54)=.19, p=.67$ and no interactions with verbal frame were significant, all $p \mathrm{~s}>.11$.

Context interacted significantly with task-type, $F(1,54)=4.54, p=.038$, partial $\eta^{2}=$ .078. Bonferroni corrected t-tests $(p=.025)$ showed that children imitated movement-styles more faithfully in NIC than in IC on both the object-related tasks (NIC: $M=1.67, S E=.071$; IC: $M=1.04, S E=.101) ; t(57)=5.57, p<.001$, Cohen's $d=.73)$ and the body-related tasks (NIC: $M=1.17, S E=.099 ;$ IC: $M=.828, S E=.102, t(57)=3.81, p<.001$, Cohen's $d=.5$ ). The difference between NIC and IC was larger on object-related tasks $\left(M_{\text {diff }}=.64\right)$ than on body-related tasks $\left(M_{\text {diff }}=.34\right), p=.04$. There was also a significant interaction between context and age-group, $F(1,54)=5.05, p=.029$, partial $\eta^{2}=.086$. The difference between NIC and IC was significant in both the younger group (NIC: $M=1.33, S E=.1 ;$ IC: $M=.67$, 
$S E=.062, t(28)=6.21, p<.001$, Cohen's $d=1.15)$ and the older group (NIC: $M=1.52, S E=$ .094 ; IC: $M=1.19, S E=.112 ; t(28)=3.18, p=.004$, Cohen's $d=.589)$, but it was larger in younger children $\left(M_{\text {diff }}=.66\right)$ than in older children $\left(M_{\text {diff }}=.33\right), p=.031$.

As in Experiment 1 we computed percentage scores (i.e., the number of times children imitated the movement-style divided by the number of times they performed the intermediate-state). The same ANOVA using these scores confirmed that the main effect of context was still significant, $F(1,53)=33.92, p<.001$, partial $\eta^{2}=.39$. Children imitated movement-styles more often in NIC $(M=.789, S E=.033)$ than in IC $(M=.539, S E=.035)$.
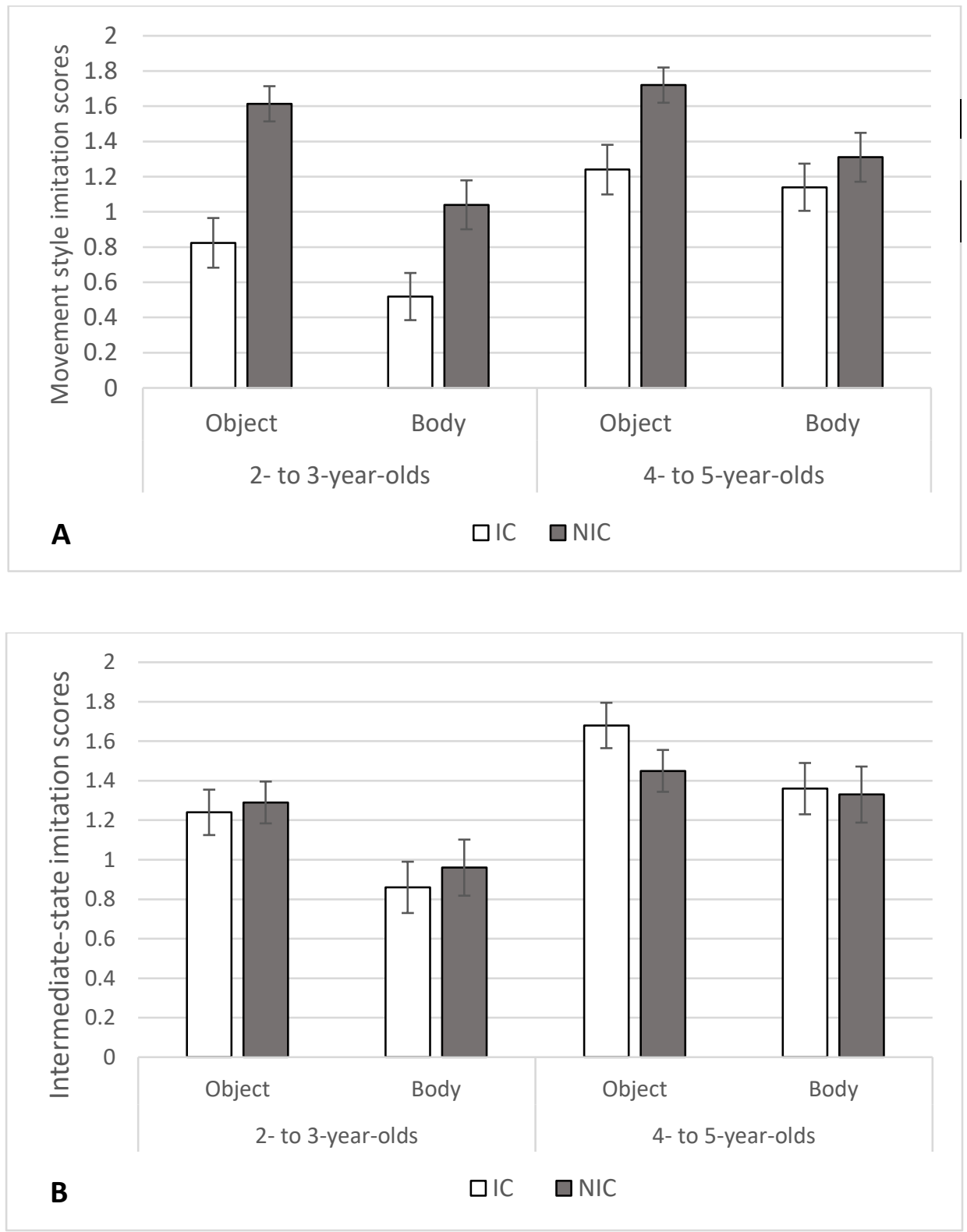


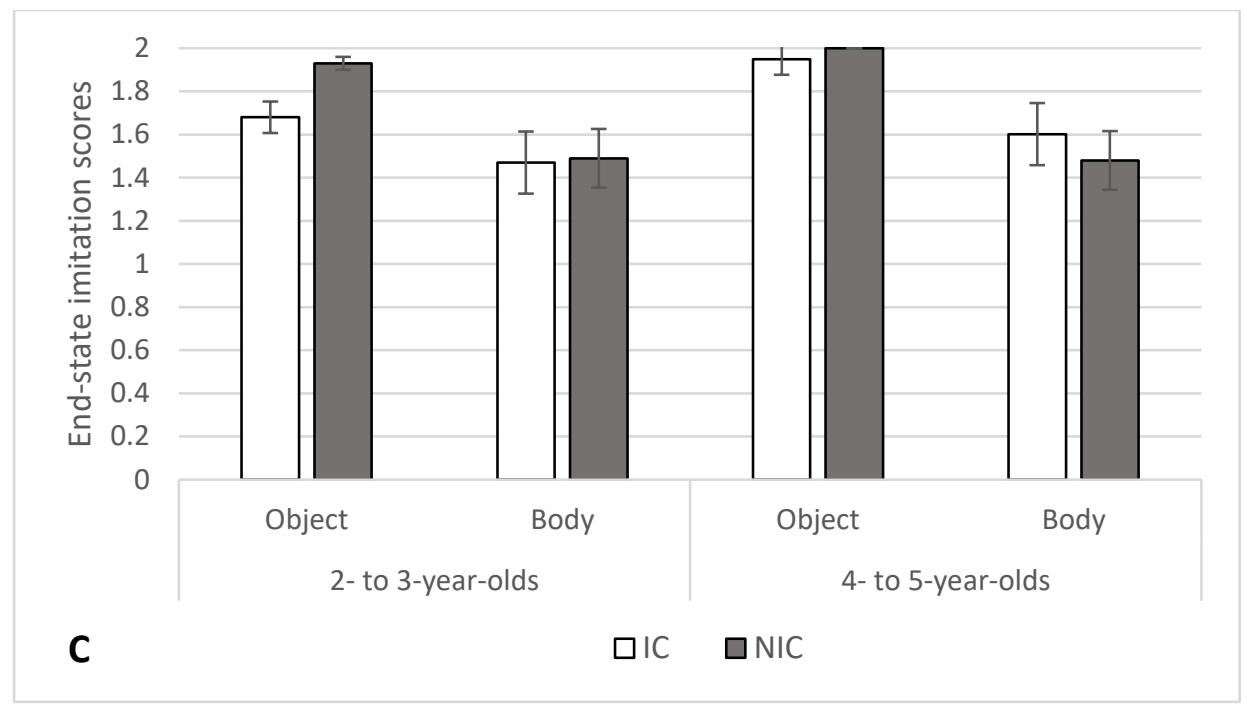

Figure 3. Imitation scores split for intermediate context (white bars: intermediate context; dark bars: no intermediate context), task-type and age groups. 3A: Movement-style. 3B: Intermediate-state. 3C: End-goal. Bars indicate standard errors.

Intermediate-state imitation. The same mixed factorial repeated-measures ANOVA was conducted on intermediate-state imitation scores (see Figure 3B). There was a significant main effect of task-type, $F(1,54)=8.584, p=.005$, partial $\eta^{2}=.137$. Intermediate-states were imitated more faithfully on object-related tasks $(M=1.42, S E=.06)$ than on body-related tasks $(M=1.13, S E=.086)$. There was also a significant main effect of age-group, $F(1,54)=$ 10.87, $p=.002$, partial $\eta^{2}=.168$. Older children imitated the intermediate-states more faithfully $(M=1.45, S E=.078)$ than the younger children $(M=1.09, S E=.078)$. No other main effects or interactions were significant, (all $p \mathrm{~s}>.07)$.

End-goal imitation. For end-goal imitation scores there was a significant main effect of tasktype, $F(1,54)=16.68, p<.001$, partial $\eta^{2}=.24$. As can be seen in Figure 3C, children produced the final goal (e.g., slotting the coins into the box) more on the object-related tasks 
$(M=1.89, S E=.03)$ than on the body-related tasks $(M=1.51, S E=.09)$. No other main effects were significant (all $p s>.2$ ).

Context interacted significantly with task-type, $F(1,54)=4.46, p=.039$, partial $\eta^{2}=.076$, and with age, $F(1,54)=4.12, p=.047$, partial $\eta^{2}=.071$. Children copied the endgoal more faithfully in NIC $(M=1.97, S E=.021)$ than in IC $(M=1.81, S E=.052)$ of the object-related tasks, $t(57)=2.74, p=.008$, Cohen's $d=.359$, but not $(p=.47)$ on the bodyrelated tasks (NIC: $M=1.48, S E=.096$; IC: $M=1.54, S E=.1$ ). Furthermore, younger children tended to copy end-goals more often in NIC $(M=1.71, S E=.07)$ than in IC $(M=$ 1.57, $S E=.09)$, but the difference was not significant, $p=.069$. Older children also had similar end-goal imitation scores between NIC $(M=1.74, S E=.07)$ and IC $(M=1.78, S E=$ $.07), p=.403$. The difference between NIC and IC was larger for younger children $\left(M_{\text {diff }}=\right.$ $.138)$ than older children $\left(M_{\text {diff }}=.035\right), p=.045$. No other interactions were significant, $p \mathrm{~s}>$ .21 .

\section{DISCUSSION}

Experiment 2 investigated whether children would copy movement-styles (e.g., hopping) less accurately when they appeared to lead to an intermediate goal (e.g., sorting coins onto plates) as opposed to when they appeared surprisingly inefficient (e.g., the coins were hopped towards an unmarked location). Replicating Experiment 1, children copied movement-styles more accurately when the action appeared inefficient (NIC) than when it achieved an intermediate external goal (IC). This difference was particularly pronounced in the objectrelated tasks and suggests that movement-styles are more likely to be imitated when they appear inefficient towards an external goal, which is common in "over-imitation" paradigms. The crucial variable investigated in Experiment 2 was action inefficiency - the results indicate that movement-based goals can be inferred in the presence of external goals, when 
these goals are achieved inefficiently. Unlike for movement-style imitation, context had no effect on intermediate-state imitation or end-state imitation on the body-related tasks. The only effect of context was to slightly increase end-state imitation on the object-related tasks. Copying an action's goal and copying its precise movements are thus likely to be distinct processes (Vivanti \& Hamilton, 2014).

Children were expected to copy end-goals more in the end-state verbal frame, because this should emphasise end-goals (Gardiner, 2014). This prediction was not confirmed. However, in Experiments 1 and 2 children were encouraged to perform the action demonstrated by the model "Now it's your turn to ...". The invitation to imitate may have encouraged faithful imitation (Hoehl et al., 2019), producing a ceiling effect on children's imitation of the end-states which overshadowed the potential effect of verbal cues. This strong imitation of the end-states suggests that children's imitation fidelity was not driven by memory limitations. This is further supported by there being no reduced imitation of the intermediate- or end-states in the IC condition. This suggests that memory limitations cannot fully explain the context effects from Experiments 1 and 2.

Our findings support the hypothesis that children interpret inefficient actions as having movement-based goals. Movement-based goals are inferred more often when movements have no external effect (Experiment 1) or bring about goals in clearly inefficient ways (Experiment 2). In the NIC condition of Experiment 2 hopping the coins towards unmarked locations did not appear efficient towards slotting the coins into the box. In contrast, hopping the coins towards colour-matched plates could be interpreted as an unrelated intermediate goal (i.e., sorting the coins onto the plates). In this case children were less likely to infer movement-based goals of hopping the coins and instead focussed on the two distinct external goals. 
There is however an alternative interpretation to our data. Leighton et al. (2010) argue that different visual cues could cause children to imitate differently between the context conditions. While in (I)C the coins were hopped towards a box (Experiment 1) or coloured plates (Experiment 2), in $\mathrm{N}(\mathrm{I}) \mathrm{C}$ the coins were hopped towards unmarked locations. Generalist accounts of imitation (e.g., the Associative Sequence Learning model; Catmur, Walsh \& Heyes, 2009) would argue that imitation in N(I)C may be enhanced because fewer visual cues can distract children from the model's actual movement. Fewer visual cues may ease imitation fidelity, instead of movement-based goal inference. Kim et al. (2015) also suggested that objects could act as external cues to goals (e.g., a box with a slit may trigger slotting), thus removing attention from movement-styles. In line with this, the difference in movement-style imitation between $\mathrm{N}(\mathrm{I}) \mathrm{C}$ and (I)C was greater in the object-related tasks than the body-related tasks in Experiments 1 and 2. Furthermore on the object-related tasks children imitated the end-state in tendency more in NIC than in IC. This could be due to visual cue differences - more objects in IC could have distracted children from the movement-style. Therefore, in Experiment 3 we explicitly controlled for whether children's imitation on object-related tasks was driven by the number of visual cues present.

\section{EXPERIMENT 3}

To isolate the effect of visual cues on imitation we compared $\mathrm{C}$ of Experiment 1 with NIC of Experiment 2. A potentially critical difference between these conditions was that in $\mathrm{C}$ the movements were directed towards the end-goal (e.g., coins were hopped directly towards and slotted into the box) whereas in NIC of Experiment 2 the movements were directed towards an unmarked location, before the coins were slotted into the box (thus appearing inefficient). In these conditions, the number of objects present and the number of actions performed were matched. The only difference is that the hopping action appears more inefficient in NIC than in C. Schachner and Carey (2013, Experiment 3) found that adults' movement-based goal 
inference was driven by the movement's perceived inefficiency. Thus, we predicted that children would be more likely to infer movement-based goals in NIC where the movementstyle appears inefficient towards the external goal. Such a finding would challenge the claim that the context effects in our previous experiments were caused by differences in visual cues, as both conditions used identical materials in Experiment 3. As the crucial factor in Experiment 3 was the amount of visual cues present, we did not include body-related tasks, although we note that the effect of context was observed for the body-related tasks in Experiments 1 and 2. As the visual information was identical across conditions in the bodyrelated tasks, this suggests already that visual cues were not driving imitation fidelity. Finding a similar effect on the object-related tasks would strengthen our interpretation of the context effect. Also, as Experiment 2 found no difference between the two verbal frame conditions, in Experiment 3 all actions were described using the novel labels like in Experiment 1 .

Participants. Participants were 36 children (14 female, $M_{\text {age }}=47.2$ months, $S D=4.8$ months, range: $36-60$ months). We split the sample via median age producing a group of children under 4 years ( $n=20,8$ female) and a group who were 4 years and older ( $n=16,6$ female). Ethical approval was granted by the University of _'s Social Sciences Research Ethics Committee.

Materials and Procedure. The materials and procedure were identical to those in $\mathrm{C}$ of Experiment 1 and NIC of Experiment 2 (see Figure 2). In a within-participants design, children saw two NIC tasks and two C tasks. Critically, the movements were identical in duration between the NIC and C conditions. Condition and task-order were counterbalanced within-participants. 
Coding. Coding was performed in situ by the experimenter. The experimenter recorded whether children reproduced the movement-styles of each action, using the criteria from Experiments 1 and 2. An observer coded $40 \%$ the data in situ alongside the experimenter. Agreement between the experimenters was perfect.

Results. There were no significant effects of gender or context-order on the imitation scores, all $p s>.1$. These variables are not considered further.

Movement style imitation. We conducted a 2 (context: external context C vs. no intermediate context NIC; within-subjects) $\times 2$ (age -group: younger vs. older, between-subjects) mixed factorial repeated-measures ANOVA on movement-style scores (see Figure 4A). We found a significant main effect of context, $F(1,34)=4.35, p=.045$, partial $\eta^{2}=.113$, but no main effect of age-group, $F(1,34)=1.81, p=.188$, partial $\eta^{2}=.05$. Children were more likely to copy the movement-style in NIC $(M=1.52, S D=.59)$ than in $\mathrm{C}(M=1.18, S D=.64)$. Context did not interact with age, $F(1,34)=.29, p=.59$, partial $\eta^{2}=.009{ }^{1}$

End-goal imitation. We conducted the same ANOVA on end-goal imitation scores (see Figure 4B). There was no significant main effect of context, $F(1,34)=3.421, p=.071$, partial $\eta^{2}=.091$, or of age-group, $p>.99$. Context did not interact with age-group, $F(1,34)=$ $1.52, p=.226$, partial $\eta^{2}=.043$.

\footnotetext{
${ }^{1}$ Whilst Experiment 3 presents new data, we also compared condition C in Experiment 1 and NIC of Experiment 2 in our existing data. The results showed that children copied movement-styles more faithfully in NIC $(M=1.83, S E=.084)$ than in C $(M=1.1, S E=.139), t(47.9)=4.52, p<.001$, Cohen's $d=1.16$. This strengthens our interpretation that identical movements are imitated differently depending on their perceived inefficiency.
} 

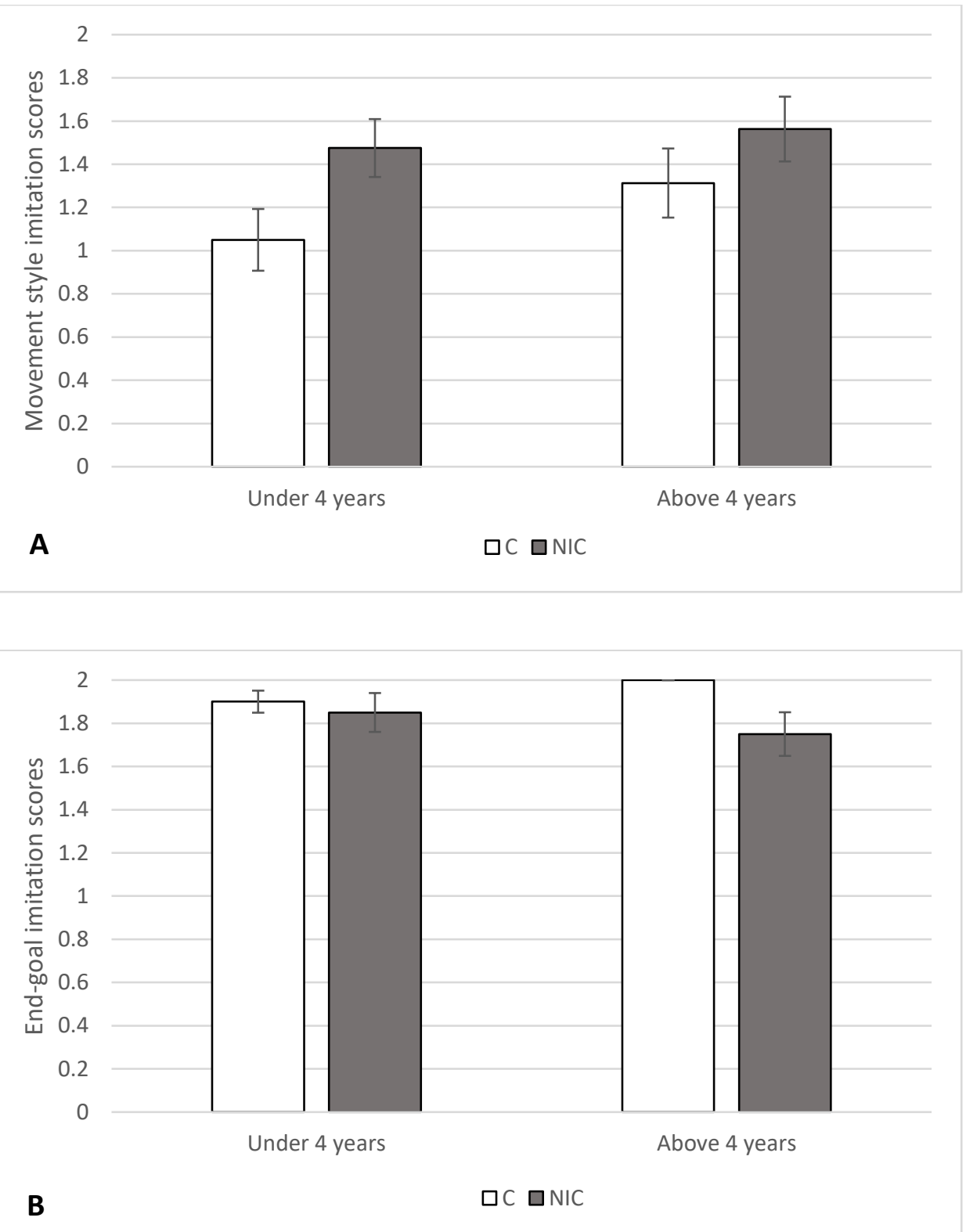

Figure 4. Imitation scores split for context (white bars: context, C; dark bars: no intermediate context, NIC) for both age groups. 4A: Movement-style. 4B: End-goal. Bars indicate standard errors.

\section{DISCUSSION}

Experiment 3 investigated whether visual information accounted for the context effects in the object-related tasks of Experiments 1 and 2. Even when the number of actions and objects were kept constant, children imitated identical movements more faithfully when they appeared more inefficient towards an external goal. However, the effect of context in 
Experiment 3 was smaller than in Experiments 1 and 2. Controlling for visual information may have reduced the effect of context, suggesting that visual cues can indeed affect imitation (Mizuguchi, Sugimura, Suzuki \& Deguchi, 2011). This claim is compatible with the movement-based goal inference account - imitation is a multi-faceted phenomenon undoubtedly affected by general action processing mechanisms. Yet, our findings cannot be fully explained by the amount of visual information to be processed (Catmur et al., 2009).

\section{GENERAL DISCUSSION}

In three experiments we investigated whether pre-schoolers' imitation is affected by varying the goal that can be attributed to agents' actions. Experiment 1 replicated previous findings (Bekkering et al., 2000; Carpenter et al., 2005) that children imitate identical movementstyles more precisely when they were performed without obvious external goals. This effect was pronounced on object-related tasks and was not observed for end-goal imitation. In Experiment 2, we compared conditions where identical movements were either seen as achieving an end-goal via an intermediate-goal or just achieving the end-goal inefficiently. Consistent with Experiment 1, movement-styles were copied more accurately when end-goals were achieved inefficiently. In contrast, context had no effect on whether children replicated the intermediate-states and end-goals. Experiment 3 confirmed that this context-specific effect on movement-styles was not fully explained by visual cue differences Taken together, children imitated the model more faithfully when their actions appeared inefficient.

We suggest that this was due to children inferring that the model's actions were being performed "for their own sake". In Experiment 1, children imitated actions more faithfully when they were performed without external goals, suggesting that movement-based goals were inferred in the absence of said external goals. Results from Experiments 2 and 3 suggest 
that the presence of external goals does not preclude movement-based goal inference actions achieving external goals in inefficient ways can also be attributed movement-based goals. The context effect on movement-style imitation fidelity cannot be explained by memory limitations: in Experiments 1 and 2 the context effect occurred on the body-related tasks and there was no context effect on intermediate- or end-state imitation in Experiment 2. Likewise the context effect on movement-style imitation cannot be explained by differences in visual cues, as the effect occurred in Experiment 3 where visual cues were held constant. Taken together, our findings indicate that children were more likely to infer movement-based goals both for actions performed without external goals and actions achieving external goals inefficiently.

To infer movement-styles as goals in themselves, pre-schoolers need the ability to infer likely goals for each action within the demonstrated action sequence. Loucks, Mutschler and Meltzoff (2017) showed that 3-year-olds can indeed infer separate goals for different actions, even when these actions are presented in an interleaved fashion. Children interpret movements as goals in themselves similarly to adults (Wakefield et al., 2018). Movements are seen as goals if they are inefficient towards an observed external goal, or seemingly voluntary in the absence of any external goal. In adults, this inference is suggested to be a form of inverse planning, following Bayesian inference (Baker et al., 2009). Goals are evaluated based on their prior probability, and then weighed against observed actions as likely explanations of behaviour. This process allows movements to be viewed as goals if no other explanation fits. Children may use the same process of Bayesian inverse planning to infer goals as pre-schoolers use Bayesian inference for causal inferences (Sobel, Tenenbaum \& Gopnik, 2004) and word learning (Xu \& Tenenbaum, 2007).

The movement-based goal inference account is compatible with the rational imitation literature. Gergely and colleagues (e.g., Gergely \& Csibra, 2003; Gergely \& Jacob, 2012) 
argue that children imitate irrelevant actions because they believe that intentional actions are done for good reasons. This 'principle of rational action' hypothesises that people's actions help them achieve goals, and actions are attempted efficiently. When someone performs an action in an inefficient way, there must be some unknown reason for doing so (Gergely et al., 2002). Movement-based goal inference could be a more specific formulation of this process. The goal ascribed to an agent (the "unknown reason") is determined by action characteristics (Baker et al., 2008). In our study, children imitated identical actions more faithfully when they were performed inefficiently because these are more likely to be interpreted as being performed for their own sake. Movement-based goal inference is thus compatible with the principle of rational action.

We do not claim that the movement-based goal inference account provides a unified theory of over-imitation. Even though there is evidence that when young children recognise that actions are performed for their own sake, they copy these actions more faithfully (Horner \& Whiten, 2005; Kenward, 2012; Marsh et al., 2014), there is also evidence that children copy actions not performed in contact with a reward container less often than actions touching said container (Lyons et al., 2007; Taniguchi \& Sanefuji, 2017). This is not predicted by the movement-based goal inference account which argues that actions performed with no external goal should be imitated more faithfully. Encouraging movementbased goal inference may only foster faithful imitation in games or rituals, rather than when achieving a functional end (i.e., retrieving rewards from a box). Young children will imitate irrelevant actions less when with a model who displays no interest in those actions. Nielsen et al. (2015) conducted a study where, after watching a model demonstrate irrelevant actions (e.g., tapping a box before opening it), 4-year-olds interacted with models expressing different requests. Children reproduced irrelevant actions more often when invited to play by the model than in the presence of a third party who wanted a different outcome (i.e., 
retrieving their toy from the box). Children were more likely to omit irrelevant actions to retrieve the third party's toy. Whilst pre-schoolers may recognise that models have movement-based goals for performing unusual actions, Nielsen et al.'s findings show that one must also consider whether children wish to reproduce movement-based goals. Future work should investigate under which circumstances children feel compelled to imitate such goals. Our findings provide a preliminary hypothesis - in simple one-to-one games, children may imitate actions that indicate movement-based goals. This may not occur with a third party who expresses a different goal (Nielsen et al., 2015).

Several future directions would benefit the arguments made here. Firstly, our results require replication across other tasks. We argue that movements will be inferred as goals if they appear inefficient towards a known external goal or if there is no external goal. As imitation is affected by different processes depending on the action being performed (Jones, 2007), movement-based goals may be inferred more easily for some over-imitation tasks than others. The level of inefficiency of the 'irrelevant' actions on over-imitation tasks may determine the likelihood of children performing those actions faithfully. A review of how much movement-based goal inference can explain over-imitation in other imitation tasks would be beneficial to develop our account.

Secondly, we predict abilities other than imitation to be affected by movement-based goal inference. One proposal is that children should also make predictions consistent with movement-based goals for an agent's future actions. Schachner and Carey (2013) asked adults to watch a cartoon about a box that moved and jumped from side to side (Experiment 1). They then paused the videos and asked participants to make predictions about where the agent would move next on the screen. Adults who inferred movement-based goals for the agent's actions expected them to continue their movement pattern. In contrast, adults who inferred external goals were far less likely to believe that the agent would continue the 
movement pattern. Investigating whether children's action prediction varies with the apparent inefficiency of agents' actions would strengthen our interpretation, by showing that action prediction and action inference are affected by the same variables.

In conclusion, we show that children copy movements more accurately (a) when movements do not bring about an external goal and (b) when movements are clearly an inefficient means to bring about an external goal. In addition to other explanations suggesting that increased imitation of actions without obvious external goals is due to differences in the amount of visual information present, we propose that accuracy of imitation can be determined by movement-based goal inference for actions that are not causal or functional to an intended outcome. This finding expands current attempts to make sense of "overimitation" by providing evidence that high-fidelity imitation of arbitrary actions may be an instance of movement-based goal inference. Future work along the lines suggested above will strengthen our theoretical approach by showing the extent to which goal inference affects imitation across tasks and by investigating the role of goal inference in other abilities. 
References

Baker, C, Goodman, N. \& Tenenbaum, J. (2008). Theory-based social goal inference. Proceedings of the $30^{\text {th }}$ Annual Conference of the Cognitive Science Society, 14471452.

Baker, C., Saxe, R., \& Tenenbaum, J. (2009). Action understanding as inverse planning. Cognition, 113, 329-349. doi.1016/j.cognition.2009.07.005

Bekkering, H., Wohlschläger, A., \& Gattis, M. (2000). Imitation of gestures in children is goal-directed. Quarterly Journal of Experimental Psychology, 53A, 153-164. doi: $10.1080 / 713755872$

Carpenter, M., Call, J. \& Tomasello, M. (2005). Twelve- and 18-month-olds copy actions in terms of goals. Developmental Science, 8, F13-F20. doi: 10.1111/j.14677687.2004.00385.x

Carpenter, M., Nagell, K. \& Tomasello , M.(1998). Social cognition, joint attention, and communicative competence from 9 to 15 month of age. Monographs of the Society for Research in Child Development. doi: 10.2307/1166214

Catmur, C., Walsh, V., \& Heyes, C. (2009). Associative sequence learning: The role of experience in the development of imitation and the mirror system. Philosophical Transactions of the Royal Society B: Biological Sciences, 364, 2369-2380. doi: 10.1098/rstb.2009.0048

Elsner, B. (2007). Infants' imitation of goal-directed actions: The role of movements and action effects. Acta Psychologica, 124, 44-59. doi:10.1016/j.actpsy.2006.09.006 
Elsner, B., \& Pfeifer, C. (2012). Movement or goal: Goal salience and verbal cues affect preschoolers' imitation of action components. Journal of Experimental Child Psychology, 112, 283-295. doi: 10.1016/j.jecp.2012.02.010

Froese, T., \& Leavens, D. (2014). The direct perception hypothesis: Perceiving the intention of another's action hinders its precise imitation. Frontiers in Psychology, 5. doi: 10.3389/fpsyg.2014.00065

Gardiner, A. (2014). Beyond irrelevant actions: Understanding the role of intentionality in children's imitation of relevant actions. Journal of Experimental Child Psychology, 119, 54-72. doi: 10.1016/j.jecp.2013.10.008

Gergely, G., Bekkering, H. \& Király, I. (2002). Rational imitation in preverbal infants. Nature, 415 , 755. doi: $\underline{10.1038 / 415755 a}$

Gergely, G., \& Csibra, G. (2003). Teleological reasoning in infancy: The naïve theory of rational action. Trends in Cognitive Sciences, 7, 287-292. doi: 10.1016/S13646613(03)00128-1

Gergely, G. \& Jacob, P. (2012). Reasoning about instrumental and communicative agency in human infancy. Advances in Child Development and Behaviour, 43, 59-94. doi: $\underline{10.1016 / B 978-0-12-397919-3.00003-4}$

Gleissner, B., Meltzoff, A., \& Bekkering, H. (2000). Children's coding of human action: cognitive factors influencing imitation in 3-year-olds. Developmental Science, 3, 405414. doi: $10.1111 / 1467-7687.00135$

Hoehl, S., Keupp, S., Schleihauf, H., McGuigan, N., Buttelmann, D. \& Whiten, A. (2019). 'Over-imitation': a review and appraisal of a decade of research. Developmental Review, 51, 90-108. doi: 10.1016/j.dr.2018.12.002 
Horner, V., \& Whiten, A. (2005). Causal knowledge and imitation/emulation switching in chimpanzees (Pan troglodytes) and children (Homo sapiens). Animal Cognition, 8, 164-181. doi: 10.1007/s10071-004-0239-6.

Jones, S. (2007). Imitation in infancy: the development of mimicry. Psychological Science, 18, 593-599. doi: 10.1111/j.1467-9820.2007.01945.x

Kenward, B. (2012). Over-imitating preschoolers believe unnecessary actions are normative and enforce their performance by a third party. Journal of Experimental Child Psychology, 112, 195-207. doi: 10.1016/j.jecp.2012.02.006

Keupp, S., Bancken, C., Schillmöller, J., Rakoczy, H., \& Behne, T. (2016). Rational overimitation: Preschoolers consider material costs and copy causally irrelevant actions selectively. Cognition, 147, 85-92. doi: 10.1016/j.cognition.2015.11.007

Keupp, S., Behne, T. \& Rakoczy, H. (2013). Why do children overimitate? Normativity is crucial. Journal of Experimental Child Psychology, 116, 392-406. doi: 10.1016/j.jecp.2013.07.002

Kim, Z., Óturai, G., Király, I. \& Knopf, M. (2015). The role of effects and action type in action imitation: Comparing the imitation of object-related actions vs. gestures in 18month-old-infants. Infant Behavior and Development, 41, 43-51. doi: 10.1016/j.infbeh.2015.07.002

Leighton, J., Bird, G., \& Heyes, C. (2010). 'Goals' are not an integral component of imitation. Cognition, 114, 423-435. doi: 10.1016/j.cognition.2009.11.001

Lombrozo, T. (2010). Causal-explanatory pluralism: How intentions, functions, and mechanisms influence causal ascriptions. Cognitive Psychology, 61, 303-332. doi: 10.1016/j.cogpsych.2010.05.002 
Loucks, J., Mutschler, C., \& Meltzoff, A. (2017). Children's representation and imitation of events: How goal organization influences 3-year-old children's memory for action sequences. Cognitive Science, 41, 1904-1933. doi: 10.1111/cogs.12446

Lyons, D., Damrosch, D., Lin, J., Macris, D., \& Keil, F. (2011). The scope and limits of overimitation in the transmission of artefact culture. Philosophical Transactions of the Royal Society B: Biological Sciences, 366, 1158-1167. doi: 10.1098/rstb.2010.0335

Lyons, D., Young, A., \& Keil, F. (2007). The hidden structure of overimitation. Proceedings of the National Academy of Sciences, 104, 19751-19756. doi: 10.1073/pnas.0704452104

Marsh, L. E., Ropar, D. \& Hamilton, A. F. de C. (2014). The social modulation of imitation fidelity in school-age children. PLoS One, 9, e86127. doi: 10.1371/journal.pone.0086127

McGuigan, N., Makinson, J., \& Whiten, A. (2011). From over-imitation to super-copying: Adults imitate causally irrelevant aspects of tool use with higher fidelity than young children. British Journal of Psychology, 102, 1-18. doi: 10.1348/000712610X493115

Mizuguchi, T., Sugimura, R., Suzuki, R. \& Deguchi, T. (2011). Children's imitation is affected by goals, but the goals are outstanding action characteristics rather than action outcomes. Scientific Research, 2, 869-874. doi: 10.4236/psych.2011.28132

Moraru, C., Gomez, J., \& McGuigan, N. (2016). Developmental changes in the influence of conventional and instrumental cues on over-imitation in 3- to 6-year-old children. Journal of Experimental Child Psychology, 145, 34-47. doi:

10.1016/j.jecp.2015.11.017 
Nielsen, M. (2006). Copying actions and copying outcomes: Social learning through the second year. Developmental Psychology, 42, 555-565. doi: 10.1037/07357036.107.2.174

Nielsen, M., \& Blank, C. (2011). Imitation in young children: when who gets copied is more important than what gets copied. Developmental Psychology, 47, 1050-1053. doi: $10.1037 / \mathrm{a} 0023866$

Nielsen, M., Kapitány, R. \& Elkins, R. (2015). The perpetuation of ritualistic actions as revealed by young children's transmission of normative behavior. Evolution and Human Behavior, 36, 191-198. doi: 10.1016/j.evolhumbehav.2014.11.002

Nielsen, M., \& Tomaselli, K. (2010). Overimitation in kalahari bushman children and the origins of human cultural cognition. Psychological Science, 21, 729-736. doi: 10.1111/j.1467-7687.2008.00722.x

Novack, M. A., Wakefield, E. M. \& Goldin-Meadow, S. (2016). What makes a movement a gesture? Cognition, 146, 339-348. doi: 10.1016/j.cognition.2015.10.014

Over, H., \& Carpenter, M. (2012). Putting the social into social learning: Explaining both selectivity and fidelity in children's copying behavior. Journal of Comparative Psychology, 126, 182-192. doi: 10.1037/a0024555

Paulus, M. (2012). Is it rational to assume that infants imitate rationally? A theoretical analysis and critique. Human Development, 55, 107-121. doi: 10.1159/000339442

Rakoczy, H., Warneken, F. \& Tomasello, M. (2008). The sources of normativity: young children's awareness of the normative structure of games. Developmental Psychology, 44, 875-881. doi: $\underline{10.1037 / 0012-1649.44 .3 .875}$ 
Schachner, A., \& Carey, S. (2013). Reasoning about 'irrational' actions: When intentional movements cannot be explained, the movements themselves are seen as the goal. Cognition, 129, 309-327. doi: 10.1016/j.cognition.2013.07.006

Schneider, D., Slaughter, V., \& Dux, P. (2017). Current evidence for automatic Theory of Mind processing in adults. Cognition, 162, 27-31. doi: 10.1016/j.cognition.2017.01.018

Sobel, D., Tenenbaum, J., \& Gopnik, A. (2004). Children's causal inferences from indirect evidence: Backwards blocking and Bayesian reasoning in preschoolers. Cognitive Science, 28, 303-333. doi: 10.1016/j.cogsci.2003.11.001

Stone, W., Ousley, O., \& Littleford, C. (1997). Motor imitation in young children with autism: What's the object? Journal of Abnormal Child Psychology, 25, 475-485. doi: 10.1023/A:1022685731726

Taniguchi, Y. \& Sanefuji, W. (2017). The boundaries of overimitation in preschool children: Effects of target and tool use on imittaion of irrelevant actions. Journal of Experimental Child Psychology, 159, 83-95. doi: 10.1016/j.jecp.2017.01.014.

Vivanti, G. \& Hamilton, A. (2014). Imitation in autism spectrum disorders. In F.R. Volkmar, S. J. Rogers, R. Paul \& K. A. Pelphrey (Eds.), Handbook of autism and pervasive developmental disorders, $4^{\text {th }}$ edition (pp.278-301). John Wiley \& Sons, Inc. doi: 10.1002/9781118911389.hautc12

Wakefield, E. M., Novack, M. A. \& Goldin-Meadow, S. (2018). Unpacking the ontogeny of gesture understanding: how movement becomes meaningful across development. Child Development, 89, 245-260. doi: 10.1111/cdev.12817 
Xu, F. \& Tenenbaum, J. B. (2007). Word learning as Bayesian inference. Psychological Review, 114, 245-272. doi: 10.1037/0033-295X.114.2.245. doi: 10.1037/0033$\underline{295 X .114 .2 .245}$

Yu, Y. \& Kushnir, T. (2014). Social context effects in 2- to 4-year-olds' selective versus faithful imitation. Developmental Psychology, 50, 922-933. doi: 10.1037/a0034242

Zmyj, N., Aschersleben, G., Prinz, W., \& Daum, M. (2012). The peer model advantage in infants' imitation of familiar gestures performed by differently aged models. Frontiers in Psychology, 3. doi: 10.3389/fpsyg.2012.00252 